aqueous vapour in condensing developes positive electricity. No unusual development of electricity has ever been detected by him in a cloud when no rain is falling.

The above results, though falling short of what has to be done to complete the theory, are yet definite, and hence valuable, the more so if supported by other observers placed in equally favourable situations. But of the variations in intensity of positive or negative electricity nothing has been said.

Besides the fixed instruments at the Observatory others are used on the mountain. Gases are collected from cracks in the earth's crust, tubes being let down into them, and the gas sucked up by a kind of bellows to be examined at leisure. A portable spectroscope is also used during eruptions, and there is a larger one by Hoffman in the Observatory. From this Observatory we have received valuable information, and it is much to be regretted that equally efficient observatories have not been established in different parts of the world. Many portable and cheap instruments have been invented, most of which are described by Mr. Mallet in the "Admiralty Manual of Scientific Inquiry ;" but there ought to be three or four as delicate as that on Mount Vesuvius. It is a pity that no observatory has ever replaced the ancient one of Empedocles near the summit of Etna, or even at Nicolosi, where the valuable services of Dr. Gemellaro might have been obtained. This would have been the more interesting, as Palmieri can detect shocks caused by that volcano, though the distance is enormous. With a third observatory, say in the Philippine Islands, we could not fail to increase our knowledge enormously.

From long practice Palmieri is able to predict eruptions. We remember well when we were enjoying his hospitality at the beginning of last year how he said, "This is a small eruption, but there is going to be a great one ; I do not say it will be soon, it may be a year, but it will come." In almost exactly a year the great eruption did come.

GEORGE FORPES

\section{ON THE DISINTEGRATION OF COMETS}

$r \mathrm{HE}$ main design of the following paper is to present 1 at one view the historical evidence of the gradual disintegration of periodic comets. A few preliminary remarks, however, in regard to the received theory of comets and meteors, may not be destitute of interest.

The fact that in several instances meteoric streams move in orbits identical with those of certain comets was first fully established by the researches of Signor Schiaparelli. The theory, however, of an intimate relationship between comets and meteors was proposed and advocated by the writer several years previous to the publication of Schiaparelli's memoirs. In an article written in July $\mathbf{1 8 6 1}$, and published in the "Danville Quarterly Review" for December of that year, it was maintained-

I. That meteors and meteoric rings "are the débris of ancient, but now disintegrated comets whose matter has become distributed around their orbits."

2. That the separation of Biela's comet as it approached the sun in December 1845 was but one in a series of similar processes which would probably continue until the individual fragments would become invisible.

3. That certain luminous meteors have entered the solar system from the interstellar spaces. $t$

4. That the orbits of some meteors and periodic comets have been transformed into ellipses by planetary perturbation. And-

5. That numerous facts-some observed in ancient and some in modern times-have been decidedly indicative of cometary disintegration.

What was thus proposed as theory has been since confirmed as undoubted facts. When the hypothesis was

* The name of cometoids was accordingly proposed for luminous meteors. t Others, it was supposed, might have originated within the systemview which the writer has not wholly abandoned. originally advanced, the data required for its mathematical demonstration were entirely wanting. The evidence, however, by which it was sustained was sufficient to give it a high degree of probability.

The existence of a divellent force by which comets near their perihelia have been separated into parts, is clearly shown by the facts enumerated in the following lines. Whether this force, as suggested by Schiaparelli, is simply the unequal attraction of the sun on different parts of the nebulous mass, or whether, in accordance with the views of other astronomers, it is to be regarded as a cosmical force of repulsion, is a question left for future discussion.

I. Seneca informs us that Ephoras, a Greek writer of the fourth century B.C., had recorded the singular fact of a comet's separation into two distinct parts. * This statement was deemed incredible by the Roman philosopher, inasmuch as the occurrence was then without a parallel. More recent observations of similar phenomena leave no room to question the historian's veracity.

2. The head of the great comet of 389 A.D., according to the writers of that period, was "composed of several small stars" (Hind's "Comets," p. ro3).

3. On June 27, A.D. 416, two comets appeared in the constellation Hercules, and pursued nearly the same apparent path. Probably at a former epoch the pair had constituted a single comet. $\dagger$

4. On Aug. 4, 8I3, "a comet was seen which resembled two moons joined together." They subsequently separated, the fragments assuming different forms.+

5. The Chinese annals record the appearance of three comets-one large and two smaller ones-at the same time in the year 896 of our era. "They travelled together for three days. The little ones disappeared first, and then the large one." \$ The bodies were probably fragments of a large comet which, on approaching the sun, had been separated into parts a short time previous to the date of their discovery.

6. The third comet of I6I8.-The great comet of I6I8 exhibited decided symptoms of disintegration. When first observed (on November 30), its appearance was that of a lucid and nearly spherical mass. On the eighth day the process of division was distinctly noticed, and on the 2oth of December it resembled a cluster of small stars.

7. The comet of $166 \mathrm{r}$. - The elements of the comets of I532 and I66I have a remarkable resemblance, and previous to the year 1790 astronomers regarded the bodies as identical. The similarity of the elements is seen at a glance in the following table :-

\begin{tabular}{|c|c|c|}
\hline ihelio & $\begin{array}{l}\text { Comet of } 1532 . \\
\text {. I I I } 48^{\prime}\end{array}$ & $\begin{array}{l}\text { Comet of } 166 \mathrm{x} \\
\quad \text { I } 15^{\circ} 16^{\prime}\end{array}$ \\
\hline Longitude of $A$ & . $\quad 8723$ & 8 I 54 \\
\hline Inclination & 3236 & 33 \\
\hline ihelion Distance & 0.5192 & 0.4427 \\
\hline . . . . . & Direct & Direct \\
\hline
\end{tabular}

The elements of the former are by Olbers; those of the latter by Mechain. The return of the comet about 1790 , though generally expected, was looked for in vain. As a possible explanation of this fact it is interesting to recur to an almost forgotten statement of Hevelius. This astronomer observed in the comet of 1661 an apparent breaking up of the body into separate fragments. If The case may be analogous to that of Briela's comet.

8. The identity of the comets of 1866 and 1366 , first suggested by Prof. H. A. Newton, is now unquestioned. The existence, then, of a meteoric swarm, moving in the same track, is not the only evidence of the original comet's partial dissolution. The comet of 1866 was invisible to the naked eye; that of 1366 , seen under nearly similar * "Quæst., Nat.," lib. vii., cap. xvi.

t Chambers's "Descr. Astr.,"p. 374

Ibid. p. 383 .

Hevelius, "Cometographia," p. 34x. See also Grant's "History of Physical Astronomy," p. 302. 
circumstances, was a conspicuous object. The statement of the Chinese historian that "it appeared nearly as large as a Tow measure,"* though somewhat indefinite, certainly justifies the conclusion that its magnitude has greatly diminished during the last 500 years. The meteors moving in the same orbit are doubtless the products of this gradual separation.

9. The bipartition of Biela's comet in 1845 , as well as the non-appearance of the two fragments in 1865 , when the circumstances were favourable for observation, are too well known to require more than a passing notice.

The comet of Halley, if we may credit the descriptions given by ancient writers, has been decreasing in brilliancy from age to age. The same is true in regard to several others believed to be periodic. The comet of A.D. 1097 had a tail $50^{\circ}$ long. At its return, in March 1840 , the length of its tail was only $5^{\circ}$. The third comet of 1790 and the first of 1825 are supposed, from the similarity of their elements, to be identical. Each perihelion passage occured in May, yet the tail at the former appearance was $4^{\circ}$ in length, at the latter but $2 \frac{1}{2}^{\circ}$. In short, instances are not wanting of this apparent gradual dissolution. It would seem, indeed, extremely improbable that the particles driven off from comets in their approach to the sun, forming tails extending millions of miles from the principal mass, should again be collected around the same nuclei.

The fact, then, that comets and meteors move in the same orbits is but a consequence of that disruptive process so clearly indicated by the phenomena described. In this view of the subject, comets-even such as move in elliptic orbits-are not to be regarded as permanent members of the solar system. Their débris, however, thus scattered through space, and subject more or less to planetary perturbation, may casually penetrate the atmosphere, producing the phenomena of sporadic meteors.

DANIEL KIRKWOOD

\section{NEWTON'S MANUSCRIPTS AND BIRTH- $P L A C E$}

$A$ LL Trinity men will, like myself, regret that Lord A Portsmouth's gift, recorded in NATURE of June 6, should have been made to the library of Newton's University instead of to that of Newton's College. Surely for many reasons Trinity library is the most fitting depository for the Newton manuscripts. A catalogue of these papers is given in Collet's " Relics of Literature, 1823," pp. I90-I94, consisting of eighty-two manuscripts, said to cover nearly eight thousand pages, mostly quarto or folio, besides six note-books, and many letters to Newton in English, French, and Latin. Unfortunately many of these papers relate to biblical or theological subjects.

When Dr. Pellet, by request of Newton's executors, examined these papers with a view to publication, he condemned all but five. These were :-

a 56 half sheets in folio, De Motu Corporum.

$\beta 3 \mathrm{r}$ half-sheets in folio, being paradoxical questions concerning Athanasius (sic).

$\gamma$ I 2 half-sheets folio, an abstract of chronology, and 92 half-sheets folio, the chronology.

$\delta$ I 44 quarter-sheets, and 95 half-sheets folio, being loose mathematical papers.

$\epsilon 40$ half-sheets folio, the "History of the Prophecies," in ten chapters, and part of eleventh unfinished.

of these $\gamma$ was to have been printed, and $a, \beta$, and parts of $\delta$ and $\epsilon$ were to be reconsidered.

While on this subject, permit me to add an account of the present state of Newton's birthplace sent me by a lady at Stoke Rochford, where Newton attended a dame's school before going to the free school at Grantham :-

"Woolsthorpe, the birthplace of Sir Isaac Newton, is * Williams's "Chinese Observations of Comets," p. 73. about half-a-mile westward from Colsterworth, and nine miles from Grantham. It has been thoroughly repaired by its present owner. At the top of the staircase, in a room to the left, Newton was born on Dec. 25,1642 . Over the fireplace is a small white marble slab recording the fact, with the well-known lines parodying Genesis i. 3. The only things in this room which remain unchanged since Newton's time are the door, which is massive, and rather ornamental in its workmanship, and a small cupboard close to the fireplace, the door of which is curiously carved. In another room a singular piece of furniture, made of wainscoting, stands in one of the corners, which looks like a small apartment taken from the main room. It is said to have contained Newton's books, instruments, \&c. Above the door in front there is a shield with crossbones, and a few words to denote that the house was the birthplace of Newton. The sun-dial which Newton made and put upon the south side of his house was sent to the British Museum some thirteen or fourteen years ago."

C. M. I NGLEBY

\section{NOTES}

WE are informed that Dr. Sharpey, who has for so many years filled with such great advantage to Science and personal distinction the post of Biological Secretary to the Royal Society, has recently sent in his resignation of that appointment. There is a very general hope among Fellows of the Royal Society that Prof. Huxley may allow himself to be nominated as his successor.

AT the meeting of Convocation of the University of Oxford, held last week, the honorary degree of D.C.L. was conferred on the following gentlemen :-Samuel David Gross, M.D. and LL.D., Professor of Surgery in the Jeaffreson Medical College of Philadelphia ; Sir Benj. Collins Brodie, Bart., M. A., F.R.S., late Waynflete Professor of Chemistry ; George Burrows, M.D., of Caius College, Cambridge, F.R.S., President of the Royal College of Physicians of London, and formerly President of the General Medical Council.

THE choice of the electors of the Waynflete Professorship of Chemisty at Oxford, vacant by the resignation of Sir B. C. Brodie, has fallen on Prof. Odling, F.R.S., who at present holds the position of Fullerian Professor of Chemistry to the Royal Institution, and Examiner in Chemistry to the Unirersity of London.

Mr. Edwin Ray Lankester, B.A., late junior studen*, Christ Church, has been elected to a Natural Science Scholar ship at Exeter College, Oxford. Mr. Lankester was elected to the Burdett Coutts Scholarship in 1869, and to the Radcliffe Travelling Fellowship in 1870 . There were four candidates.

IN accordance with the intimation which we gave last week, Mr. G. B. Airy has been gazetted a K.C. B., a graceful acknowledgment of the claims of representative men of science to recog. nition by the State.

WE have to record the death, on the $16 \mathrm{th}$ inst., in his $82 \mathrm{nd}$ year, of Colonel W. H. Sykes, F.R.S., M.P. for Aberdeen. He was a distinguished officer of the East India Company, and occupied the post of chairman of its Board of Directors at the time of the surrender of its Imperial functions. Colonel Sykes was always a firm friend to scientific research, and was himself possessed of no mean scientific attainments.

MesSr. C. F. J. YULE and W. J. Sollas have been elected to Foundation Scholarships for proficiency in Natural Sciences at St. John's College, Cambridge. Each has been twice placed in the first class in the College Examination in Natural Sciences, and Mr. Sollas obtained in 1870 the exhibition of $50 l$. per annum offered by the College for competition to students in Natural Science not yet members of the University. 